\title{
3.2.
}

\section{Derecho a la salud en el Sistema Interamericano de Derechos Humanos}

Right to health in the American System of Human Rights

\section{Ricardo Barona Betancourt}

Abogado, Especialista en Derecho Laboral y Relaciones Industriales y en Seguridad Social; Magister en Derechos Humanos, Estado de Derecho y Democracia en Iberoamerica; Magister en Derecho del Trabajo. Docente de Pregrado y Especialización en Derecho Laboral y Seguridad Social de la Universidad Externado de Colombia. Investigador del Centro de Investigaciones Laborales de la Universidad Externado de Colombia. Miembro del Comité de Redacción de la Revista Internacional y Comparada Relaciones Laborales y Derecho de Empleo (México). Bogotá, Colômbia.

Resumen: En los países Latinoamericanos, se observan violaciones al derecho a la salud, pero existen pocas reclamaciones por violación a dicho derecho ante el Sistema Interamericano de Derechos Humanos. Por tal razón, en el presente trabajo, analizamos el derecho a la salud y los principales casos de violaciones al mismo, de conformidad con la jurisprudencia de la Corte Interamericana de Derechos Humanos.

Palabras claves: Responsabilidad Civil; daños; derecho a la salud; Sistema Interamericano de Derechos Humanos.

Abstract: In Latin American countries, violations of the right to health are observed, but there are few claims for violation of that right, before the Inter-American Human Rights System. For this reason, in this paper, we analyze the right to health and major violations thereto, in accordance with the jurisprudence of the Inter-American Court of Human Rights.

Key words: Liability; damage; right to health; American System of Human Rights.

\section{Introducción}

En el Sistema Interamericano de Derechos Humanos, existen varias declaraciones y convenios que protegen el derecho a la salud.

El primero de ellos, es la Convención Americana de Derechos Humanos ${ }^{1}$ donde se establece que los Estados Partes se comprometen a adoptar providencias, tanto a nivel interno como mediante la cooperación internacional, especialmente económica y técnica, para lograr progresivamente la plena efectividad de los derechos que se derivan de las normas económicas, sociales y sobre educación, ciencia y cultura, contenidas en la Carta de la Organización de los Estados

\footnotetext{
${ }^{1}$ Artículo 26 de la Convención Americana de Derechos Humanos. Suscrita en San José de Costa Rica el 22 de noviembre de 1969, en la Conferencia Especializada Interamericana sobre Derechos Humanos.
} 
Americanos, reformada por el Protocolo de Buenos Aires, en la medida de los recursos disponibles, por vía legislativa u otros medios apropiados.

Adicionalmente, el Protocolo de San Salvador ${ }^{2}$, señala que toda persona tiene derecho a la salud, entendida como el disfrute del más alto nivel de bienestar físico, mental y social. Entonces, con el fin de hacerlo efectivo, los Estados se comprometen a reconocer la salud como un bien público y particularmente a adoptar las siguientes medidas para garantizar este derecho:

a) La atención primaria de la salud, entendiendo como tal la asistencia sanitaria esencial puesta al alcance de todos los individuos y familiares de la comunidad.

b) La extensión de los beneficios de los servicios de salud a todos los individuos sujetos a la jurisdicción del Estado.

c) La total inmunización contra las principales enfermedades infecciosas.

d) La prevención y el tratamiento de las enfermedades endémicas, profesionales y de otra índole.

e) La educación de la población sobre la prevención y tratamiento de los problemas de salud.

f) La satisfacción de las necesidades de salud de los grupos de más alto riesgo y que por sus condiciones de pobreza sean más vulnerables.

\section{Sistema Interamericano de Derechos Humanos.}

\subsection{La Comisión Interamericana de Derechos Humanos.}

La Comisión es un órgano de la Organización de los Estados Americanos creado para promover la observancia y la defensa de los derechos humanos y servir como órgano consultivo de la Organización en esta materia ${ }^{3}$. Adicionalmente, se pueden presentar denuncias o quejas ante la Comisión siempre y cuando se cumplan los requisitos de competencia y de admisibilidad que revisaremos a continuación.

\subsubsection{Requisitos de Competencia.}

\section{a) En razón a la persona.}

Las denuncias o quejas pueden presentarse por: a) Cualquier persona o grupo de personas. b) Una entidad no gubernamental legalmente reconocida en uno o más

\footnotetext{
${ }^{2}$ Artículos 9 y 10 del Protocolo Adicional a la Convención Americana sobre Derechos Humanos en materia de Derechos Económicos, Sociales y Culturales, Protocolo de San Salvador. Adoptado por la Asamblea General de la Organización de Estados Americanas el 17 de noviembre de 1988.

${ }^{3}$ Artículo 1 del estatuto de la Comisión Interamericana de Derechos Humanos.
} 
Estados miembros de la Organización de Estados Americanos ${ }^{4}$. Adicionalmente, la denuncia o queja no requiere de autorización de la víctima ${ }^{5}$, pero, deben ser existir víctimas concretas, individualizadas y determinadas no siendo admisibles peticiones realizadas en abstracto, desvinculada de los derechos de seres humanos individualizados $^{6}$. De otro lado, sólo los Estados pertenecientes al Sistema Interamericano, ya por ser partes en la Convención Americana, ya por ser miembros de la Organización de Estados Americanos, pueden ser sujetos pasivos del procedimiento ante la Comisión, la cual tiene sólo respecto de ellos la facultad de examinar su conducta y asignarles responsabilidad internacional ${ }^{7}$.

\section{b) En razón a la materia.}

La Comisión solo puede resolver las quejas o peticiones que se encuentren fundamentadas en la Convención Americana sobre Derechos Humanos y el Protocolo de San Salvador ${ }^{8}$.

\section{c) En razón al tiempo.}

La Comisión debe asegurarse que la petición o comunicación recae sobre hechos ocurridos con posterioridad a la entrada en vigor de las siguientes normas en Colombia: Convención Americana sobre Derechos Humanos (21 de junio de 1985) y el Protocolo de San Salvador (22 de octubre de 1997); y mientras las anteriores permanezcan en vigor, toda vez que la mismas no se puede aplicar con efecto retroactivo.

\section{d) En razón del lugar.}

La Comisión sólo puede conocer de quejas o peticiones que se refieran a hechos que afectan a personas bajo la jurisdicción del Estado supuestamente responsable de las violaciones a los derechos humanos alegados.

\subsubsection{Requisitos de Admisibilidad.}

\section{a) Requisitos de forma y fondo.}

Antes de iniciar el trámite de una petición o queja la Comisión debe verificar los siguientes aspectos:

\footnotetext{
${ }^{4}$ Artículo 44 de la Convención Americana de Derechos Humanos y artículo 23 del reglamento de la Comisión Interamericana de Derechos Humanos.

${ }^{5}$ Considerando 2 de la Resolución No. 59/81, caso 1954 Uruguay, 16 de octubre de 1981.

${ }^{6}$ Informe 88 del 22 de octubre de 2003 de la Comisión Interamericana de Derechos Humanos.

${ }^{7}$ Artículo 44 de la Convención Americana de Derechos Humanos y artículo 23 del reglamento de la Comisión Interamericana de Derechos Humanos.

${ }^{8}$ Artículo 44 de la Convención Americana de Derechos Humanos y artículo 23 del reglamento de la Comisión Interamericana de Derechos Humanos.
} 
a) El nombre, nacionalidad y firma de la persona o personas denunciantes 0 , en el caso de que el peticionario sea una entidad no gubernamental, el nombre y la firma de su representante o representantes legales.

b) Si el peticionario desea que su identidad sea mantenida en reserva frente al Estado.

c) La dirección para recibir correspondencia, número de teléfono, facsímil y dirección de correo electrónico.

d) Una relación del hecho o situación denunciada, con especificación del lugar $y$ fecha de las violaciones alegadas.

e) De ser posible, el nombre de la víctima, así como de cualquier autoridad pública que haya tomado conocimiento del hecho o situación denunciada.

f) La indicación del Estado que el peticionario considera responsable, por acción o por omisión, de la violación de alguno de los derechos humanos consagrados en la Convención Americana sobre Derechos Humanos y otros instrumentos aplicables, aunque no se haga una referencia específica al artículo presuntamente violado ${ }^{9}$.

\section{b) Agotamiento de recursos de jurisdicción interna.}

Para que una petición o comunicación presentada sea admitida por la Comisión, se requiere que se hayan interpuesto y agotado los recursos de jurisdicción interna, conforme a los principios del Derecho Internacional generalmente reconocidos. Sin embargo, existen las siguientes excepciones al agotamiento de los recursos internos ${ }^{10}$ :

a) No exista en la legislación interna del Estado de que se trata el debido proceso legal para la protección del derecho o derechos que se alega han sido violados.

b) No se haya permitido al presunto lesionado en sus derechos el acceso a los recursos de la jurisdicción interna, o haya sido impedido de agotarlos.

c) Haya retardo injustificado en la decisión sobre los mencionados recursos ${ }^{11}$.

d) Que los recursos no sean adecuados o efectivos ${ }^{12}$.

\footnotetext{
${ }^{9}$ Artículo 28 del reglamento de la Comisión Interamericana de Derechos Humanos.

${ }^{10}$ Literal a) numeral 1 del artículo 46 de la Convención Americana sobre Derechos Humanos.

${ }_{11}^{11}$ Artículo 31 del reglamento de la Comisión Interamericana de Derechos Humanos.

${ }^{12}$ Caso Velásquez Rodriguez VS Honduras de la Corte Interamericana de Derechos Humanos.
} 


\section{c) Plazo de interposición de la petición.}

Para que una petición o comunicación sea admitida por la Comisión, se requiere que sea presentada dentro del plazo de seis (6) meses, contados a partir de la fecha en que el presunto lesionado en sus derechos haya sido notificado de la decisión definitiva ${ }^{13}$. Adicionalmente, en caso de que sean aplicables las excepciones al agotamiento de los recursos internos, la petición deberá presentarse dentro de un plazo que, a juicio de la Comisión, sea razonable; para ello, tendrá en consideración la fecha del hecho denunciado y las circunstancias de cada caso concreto ${ }^{14}$.

\section{d) No duplicidad de procedimientos y Cosa Juzgada.}

La Comisión declarará inadmisible toda petición o comunicación que sea sustancialmente la reproducción de petición o comunicación anterior ya examinada por la Comisión u otro Organismo Internacional ${ }^{15}$.

\subsection{La Corte Interamericana de Derechos Humanos.}

La Corte es una institución judicial autónoma cuyo principal objetivo es la aplicación e interpretación de la Convención Americana sobre Derechos Humanos. Teniendo en cuenta que se ha agotado el procedimiento ante la Comisión, se puede acudir ante la Corte, siempre y cuando se cumplan los requisitos en cuanto a la persona, la materia, el tiempo y el lugar.

\section{a) En razón a la persona.}

En primer lugar, sólo los Estados del Sistema Interamericano y la Comisión tienen derecho a someter un caso a la decisión de la Corte; siempre y cuando se hayan agotados los procedimientos relacionados con el trámite ante la Comisión ${ }^{16}$. Por tal razón, los individuos o personas no pueden interponer directamente demandas a la Corte sino que deben agotar previamente el procedimiento ante la Comisión, la cual, si así lo estima conveniente, y se cumplen los requisitos obligatorios para ello, puede presentar la demanda ante la Corte. De otro lado, la Corte solo tiene competencia para conocer quejas o peticiones contra los Estados partes del Sistema Interamericano que hayan reconocido o reconozcan dicha competencia, ora por declaración especial, ora por convención especial.

\footnotetext{
${ }^{13}$ Literal b) numeral 1 del artículo 46 de la Convención Americana sobre Derechos Humanos.

${ }^{14}$ Artículo 32 del reglamento de la Comisión Interamericana de Derechos Humanos.

${ }^{15}$ Literal d) del artículo 47 de la Convención Americana sobre Derechos Humanos.

${ }^{16}$ Artículo 61 de la Convención Americana Sobre Derechos Humanos.
} 


\section{b) En razón de la materia.}

La Corte Interamericana tiene competencia sobre la Convención Americana de Derechos Humanos.

\section{c) En razón del tiempo.}

Si en el plazo de tres meses, a partir de la remisión a los Estados interesados del informe de la Comisión, el asunto no ha sido solucionado o sometido a la decisión de la Corte por la Comisión o por el Estado interesado, aceptando su competencia, la Comisión podrá emitir, por mayoría absoluta de votos de sus miembros, su opinión y conclusiones sobre la cuestión sometida a su consideración ${ }^{17}$. Es decir, la Comisión debe interponer la demanda en un plazo de tres (3) meses a partir de la emisión del informe de fondo señalado en el artículo 50 de la Convención Americana de Derechos Humanos.

\section{d) En razón del lugar.}

En términos muy sencillos, la Corte Interamericana será competente respecto a demandas que se refieran a hechos que configuren violaciones que afecten a personas sujetas a la jurisdicción del Estado que se demande.

\section{Principales Casos sobre el Derecho a la Salud.}

En primer lugar, el artículo 10 de la Convención Americana sobre Derechos Humanos señala que toda persona tiene derecho a ser indemnizada conforme a la ley en caso de haber sido condenada en sentencia firme por error judicial.

Adicionalmente, el numeral 1 del artículo 63 del mismo estatuto, indica: Cuando existan violaciones al derecho protegido, se deben realizar las reparaciones respectivas y ordenar el pago de una justa Indemnización a la parte lesionada.

Por tal razón, la Corte en materia de derecho a la salud ha revisado los siguientes casos:

\section{a) Caso Ximenes Lopez VS Brasil ${ }^{18}$}

El 22 de noviembre de 1999 la señora Irene Ximenes Lopes Miranda presentó una petición ante la Comisión Interamericana contra el Brasil, en la cual denunció los hechos ocurridos en perjuicio de su hermano, el señor Damiao Ximenes Lopes, así:

1) Era una persona con discapacidad mental, la cual fue internada el 1 de octubre de 1999 para recibir tratamiento psiquiátrico en la Casa de Reposo

\footnotetext{
${ }^{17}$ Numeral 1 del artículo 51 de la Convención Americana Sobre Derechos Humanos.

${ }^{18}$ Sentencia del 4 de Julio de 2006 de la Corte Interamericana de Derechos Humanos que resuelve el caso Ximenes López VS Brasil.
} 
Guararapes (Centro de atención psiquiátrica privado, que operaba dentro del marco del sistema público de salud del Brasil).

2) Falleció el 4 de octubre de 1999 dentro de la Casa de Reposo Guararapes, al final de tres días por maltrato en los días de internación.

Teniendo en cuenta los hechos analizados anteriormente, la Corte estableció responsabilidad del Estado Brasilero con fundamento en los siguientes aspectos:

La responsabilidad estatal también puede generarse por actos de particulares en principio no atribuibles al Estado. Las obligaciones erga omnes que tienen los Estados de respetar y garantizar las normas de protección, y de asegurar la efectividad de los derechos, proyectan sus efectos más allá de la relación entre sus agentes y las personas sometidas a su jurisdicción, pues se manifiestan en la obligación positiva del Estado de adoptar las medidas necesarias para asegurar la efectiva protección de los derechos humanos en las relaciones inter-individuales.

En relación con personas que se encuentran recibiendo atención médica, y dado que la salud es un bien público cuya protección está a cargo de los Estados, éstos tienen la obligación de prevenir que terceros interfieran indebidamente en el goce de los derechos a la vida y a la integridad personal, particularmente vulnerables cuando una persona se encuentra bajo tratamiento de salud. Es decir, los Estados tienen el deber de regular y fiscalizar toda la asistencia de salud prestada a las personas bajo su jurisdicción, como deber especial de protección a la vida y a la integridad personal, independientemente de si la entidad que presta tales servicios es de carácter público o privado.

\section{b) Caso Albán Cornejo y otros VS Ecuador ${ }^{19}$}

De acuerdo a los hechos invocados por la Comisión, Laura Susana Albán Cornejo ingresó el 13 de diciembre de 1987 al Hospital Metropolitano, institución de salud de carácter privado, situada en Quito, Ecuador, debido a un cuadro clínico de meningitis bacteriana. El 17 de diciembre de 1987 durante la noche, la señorita Albán Cornejo sufrió un fuerte dolor. El médico residente le prescribió una inyección de diez miligramos de morfina. El 18 de diciembre de ese mismo año, mientras permanecía bajo tratamiento médico, la señorita Albán Cornejo murió, presuntamente por el suministro del medicamento aplicado.

\footnotetext{
${ }^{19}$ Sentencia del 22 de Noviembre de 2007 de la Corte Interamericana de Derechos Humanos que resuelve el caso Caso Albán Cornejo y otros VS Ecuador.
} 
Con posterioridad a su muerte, sus padres, Carmen Cornejo de Albán y Bismarck Albán Sánchez presentaron una denuncia penal ante las autoridades estatales para que investigaran la muerte de su hija. Como consecuencia de lo anterior, dos médicos fueron investigados por negligencia en la práctica médica, y el proceso seguido en contra de uno de ellos fue sobreseído el 13 de diciembre de 1999, al declararse prescrita la acción penal. Respecto al otro médico, su situación jurídica se encuentra pendiente de resolución judicial.

Teniendo en cuenta los hechos analizados anteriormente, la Corte estableció responsabilidad del Estado Ecuatoriano con fundamento en los siguientes aspectos:

El deber de investigar debe cumplirse con seriedad y no como una simple formalidad condenada de antemano a ser infructuosa y debe tener un sentido y ser asumida por los Estados como un deber jurídico propio y no como una simple gestión de intereses particulares, que dependa de la iniciativa procesal de la víctima o de sus familiares o de la aportación privada de elementos probatorios, sin que la autoridad pública busque efectivamente la verdad. La debida diligencia exige que el órgano que investiga lleve a cabo todas aquellas actuaciones y averiguaciones necesarias para procurar el resultado que se persigue. De otro modo, la investigación no es efectiva en los términos de la Convención.

La prescripción en materia penal determina la extinción de la pretensión punitiva por el transcurso del tiempo, y generalmente, limita el poder punitivo del Estado para perseguir la conducta ilícita y sancionar a sus autores. Esta es una garantía que debe ser observada debidamente por el juzgador para todo imputado de un delito. Sin perjuicio de lo anterior, la prescripción de la acción penal es inadmisible e inaplicable cuando se trata de muy graves violaciones a los derechos humanos en los términos del Derecho Internacional. La jurisprudencia constante y uniforme de la Corte así lo ha señalado. En el presente caso no opera la exclusión de prescripción, porque no se satisfacen los supuestos de imprescriptibilidad reconocidos en instrumentos internacionales.

Los Estados son responsables de regular y fiscalizar la prestación de los servicios de salud para lograr una efectiva protección de los derechos a la vida y la integridad personal. Para todo ello, se requiere de la formación de un orden normativo que respete y garantice efectivamente el ejercicio de sus derechos, y la supervisión eficaz y constante sobre la prestación de los servicios de los que dependen la vida y la integridad de las personas. 


\section{c) Caso Vera Vera y otra VS Ecuador ${ }^{20}$}

El señor Pedro Miguel Vera Vera, de veinte años de edad, fue detenido el 12 de abril de 1993 por miembros de la Policía Nacional de la ciudad de Santo Domingo de los Colorados, luego de que fuera perseguido por un grupo de personas quienes aparentemente lo acusaban de haber cometido asalto y robo a mano armada y escucharse un disparo de arma de fuego. Al detenerlo, los policías notaron que presentaba una herida de bala a la altura del pecho en el costado izquierdo y lo trasladaron en taxi al Cuartel de Policía de la ciudad. Luego de ser registrado en dicho lugar, ese mismo día el señor Vera Vera fue trasladado al Hospital Regional de Santo Domingo de los Colorados, de donde fue dado de alta al día siguiente.

El 22 de abril fue llevado al Hospital Eugenio Espejo de Quito, lugar donde falleció al día siguiente a consecuencia de las lesiones "consecutivas a la penetración de proyectil de arma de fuego".

Teniendo en cuenta los hechos analizados anteriormente, la Corte estableció responsabilidad del Estado Ecuatoriano con fundamento en los siguientes aspectos:

De conformidad con el acervo probatorio del caso, la Corte determinó que durante el primer internamiento del señor Vera Vera en el Hospital Regional de Santo Domingo de los Colorados no se le realizaron exámenes o diagnósticos pertinentes a fin de determinar si era necesario someterlo a un tratamiento quirúrgico, debido a las lesiones causadas por la bala que se encontraba alojada en su cuerpo. Esto constituyó una grave negligencia médica.

Además, mientras el señor Vera Vera permaneció detenido con una herida de bala en el Centro de Detención Provisional de Santo Domingo de los Colorados, no fue sometido a una valoración física adecuada. Como resultado, el señor Vera Vera ingresó al hospital nuevamente cuando presentaba signos evidentes de complicaciones de la herida que presentaba. Por lo tanto, la Corte estimó que la atención médica recibida por el señor Vera Vera en el cuartel de policía fue negligente.

\section{d) Caso Suárez Peralta VS Ecuador ${ }^{21}$}

En julio de 2000 Melba del Carmen Suárez Peralta fue intervenida quirúrgicamente

\footnotetext{
${ }^{20}$ Sentencia del 19 de Mayo de 2011 de la Corte Interamericana de Derechos Humanos que resuelve el caso Caso Vera y Vera y otra VS Ecuador.

${ }^{21}$ Sentencia del 21 de Mayo de 2013 de la Corte Interamericana de Derechos Humanos que resuelve el caso Suárez Peralta VS Ecuador.
} 
por apendicitis en la clínica privada Minchala, que le provocó padecimientos severos y permanentes.

El proceso penal iniciado en relación con estos hechos finalizó sin resultado, debido a la falta de debida diligencia en la conducción del proceso, lo que, consecuentemente, dio lugar a la declaración de prescripción en 2005 luego de transcurridos más de cinco años de dictado el auto cabeza de proceso.

Teniendo en cuenta los hechos analizados anteriormente, la Corte estableció responsabilidad del Estado Ecuatoriano con fundamento en los siguientes aspectos:

El derecho a la integridad personal se halla directa e inmediatamente vinculado con la atención a la salud humana, y que la falta de atención médica adecuada puede conllevar la vulneración del artículo 5.1 de la Convención. Por ello, la protección del derecho a la integridad personal supone la regulación de los servicios de salud en el ámbito interno, así como la implementación de una serie de mecanismos tendientes a tutelar la efectividad de dicha regulación.

\section{Conclusiones}

1. El derecho a la salud es una garantía ampliamente reconocida en el derecho internacional de los derechos humanos, así como también, en los sistemas regionales de protección, como por ejemplo, la Carta de la Organización de Estados Americanos, la Declaración Americana de Derechos y Deberes del Hombre, la Carta Internacional Americana de Garantías Sociales, la Convención Americana sobre Derechos Humanos y el Protocolo de San Salvador.

2. El Sistema Interamericano establece que la salud es un límite a varios de los derechos civiles y políticos reconocidos en el Pacto.

3. El Pacto de San José no precisa ni define el alcance de los derechos reconocidos de manera exhaustiva, deja un amplio espacio a cada uno de los Estados para que interprete la Convención y desarrolle sus normas. No obstante, el texto de la Convención impide que se hagan lecturas perversas de la misma al prohibir expresamente que las normas sean interpretadas para lo siguiente:

a) Suprimir el goce y ejercicio de los derechos en mayor medida a la permitida.

b) Limitar el goce y ejercicio de otros derechos reconocidos nacionalmente o en otras convenciones.

c) Excluir otros derechos propios de una forma democrática representativa de gobierno. 
d) Excluir o limitar el efecto de la Declaración Americana de los Derechos Humanos o documentos internacionales de similar naturaleza. 